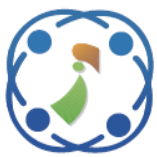

\title{
Development of a Stochastic Optimization Model and Long-Term Forecasting for Electricity Generation Planning Under Uncertainty
}

\author{
Nattapon Jaisumroum ${ }^{1 *}$ \\ Jirarat Teeravaraprug 1 \\ ${ }^{l}$ Department of Industrial Engineering, Faculty of Engineering, Thammasat University, Thailand \\ * Corresponding author’s Email: nattaponj89@gmail.com
}

\begin{abstract}
This paper is dedicated to the study of electricity generation expansion planning considering uncertainty. The method used for this problem is utilizing a highly constrained uncertainty optimization issue, as it were be solvable and complete classification. The demonstration uses a toll function to minimize environment effect and operational costs. A Neural Network is utilized to long-term forecast in electricity. The stochastic optimization model consists of finding the optimal long-term electricity generation planning for the construction of new generation capacity subject to various economic and technical constraints. The model can be showed experimental results that enable long-term planning of electricity generation with optimization of the costs, pollution emission and uncertainty of these generation resources in determining the best solution. The findings can help decision the government policy not only adjust the existing electricity generation but also coordinate the conflict interaction among system cost, energy supply, pollutant mitigation as constraint violation risk.
\end{abstract}

Keywords: Electricity generation planning, Long-term forecasting, Stochastic optimization.

\section{Introduction}

The model of electricity appears to be constantly important, not only for academic purposes but also in many government projects in the context of the formulation of electricity, energy security and climate change policies. Power systems require sustainable management to have an important role in Thailand's social and economic development. Now, fossil fuels and renewable energy are major energy sources that have serious negative outcomes for the environment locally and globally [1]. We divided the plans on electricity production as follows: longterm, mid-term, and short-term [2]. However, an optimal electric generation plan may be a troublesome issue due to the following types of power plants to work with: thermal, combined cycle, renewable and hydro power plants. This problem can be solved by various computer tools. We used least-cost generation expansion planning to figure the minimized cost capacity that meets the forecasted demand within the parameters on the planning horizon [3]. We now need to look at the costs, risks and benefits for an energy source compared with others. Thailand's national policy on energy should be aimed at implementing the systems that ensure the diversity and security of supply [4]. The Electricity Generating Authority of Thailand (EGAT) established on the 1st of May 1969 is a state enterprise which provides electric utility services for the public in Thailand, under the management of the Ministry of Finance (MOF) with the Ministry of Energy (MOE) has established a policy to provide an adequate electricity supply in the future, this policy referred as the Power Development Plan (PDP). The PDP is used to determine the future electricity expansion starting in 2018 and ending in 2036 [5]. The objective of the PDP was to reduce emissions [6]. The government of Thailand's policy on electricity for resourcefulness expansion to meet all energy demands for power generation in Thailand [7]. The PDP was completed in collaboration with the MOE and EGAT as the main power plan to enhance system stability, reduce natural gas dependence, increase the use of clean coal technology, decrease electricity purchase from other countries, and utilize of renewable energy. This research is different from 
the other researchers have presented, with separate forecasting and production control planning or control emission affect method. The stochastic model in this paper, advantages are including production control and environmental impact in long-term planning for the optimization cost in expansion electrical power plant. In present, EGAT have 47 power plants located all over Thailand with introduced capacity of 16,876 MW. The power plants of EGAT, 3 thermal generating station, 6 combined cycle generating station, 27 hydropower generating station, 9 renewable generating station, 4 diesel generating station, and 1 gas turbine generating station (Table 1). Fig. 1 shows the system's capacity as percentages of power plants of electricity station. Bulk purchases of electricity regarding 12 independent power producers (IPPs) of 14,948 MW, small power producers (SPPs) of 7,536 MW and from other regions (Laos and Malaysia) of 3,877 MW. This research focuses on identifying a suitable model for energy resource proportion and power plant for long-term electricity generations expansion planning through 2036 in Thailand. This paper aims to propose a mathematical model, stochastic optimization for a long-term electricity power system planning with neural network forecasted electricity consumption under uncertainty conditions

Table 1. The types of power plants capacity of EGAT

\begin{tabular}{|l|r|r|}
\hline \multicolumn{1}{|c|}{$\begin{array}{c}\text { Power Plant } \\
\text { Type }\end{array}$} & $\begin{array}{c}\text { Capacity } \\
\text { (MW) }\end{array}$ & \multicolumn{1}{c|}{$\begin{array}{c}\text { System } \\
(\mathbf{\%})\end{array}$} \\
\hline Thermal (TM) & $3,647.00$ & 22.69 \\
Combined cycle (CC) & $8,896.00$ & 55.36 \\
Hydropower (HP) & $2,952.40$ & 18.37 \\
Renewable (RE) & 45.33 & 0.28 \\
Diesel (DE) & 30.40 & 0.19 \\
Gas Turbine (GT) & 500.00 & 3.11 \\
\hline \multicolumn{1}{|c|}{ Total } & $\mathbf{1 6 , 0 7 1 . 1 3}$ & $\mathbf{1 0 0}$ \\
\hline
\end{tabular}

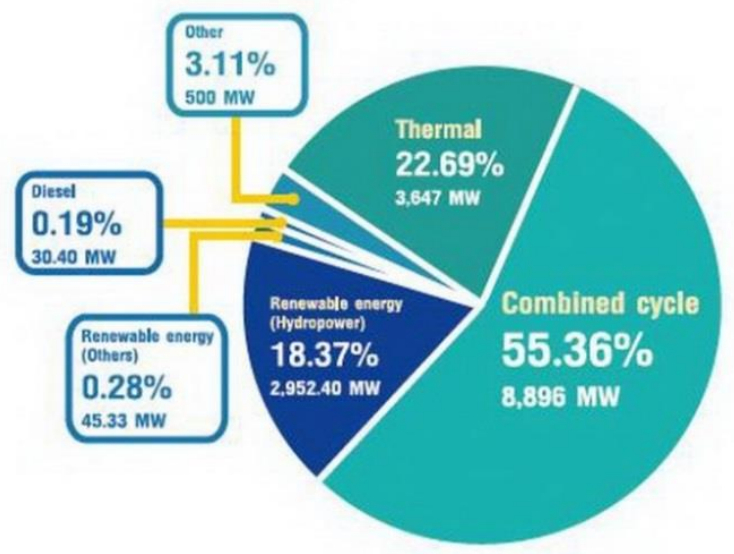

Figure.1 The capacity power plants of EGAT
In this article, we present the forecasting of electricity demand using feed-forward artificial neural network and multiple linear regression methods in consumption demand and peak load. In peak load after $\mathrm{NN}$ forecasted will be used probability distribution with load curve method. Finally, electric generation in long-term planning using a mathematical model in stochastic method for expansion the power plant under uncertainty of energy supply and technology disruption.

\section{The method development in long-term planning for electricity generation}

The model was accounted for all various electricity generation: the energy resources fossil (coal or lignite, natural gas, and fuels); and renewable resources (biomass energy, hydropower, solar, and wind) in power system. Therefore, final decision is to look at the issue with minimizing the expected value of costs by using various optimized the resource, allocation arrangement and installed capacity expansion for long-term planning schemes [8].

\subsection{Electricity demand forecasting}

In the study, the historical data of Electricity Consumption (EC) from 1990-2017 are used as the influential input indicators data, using GDP and POP for NN model, which is also proposed for 2018-2036 forecast by comparing them with a model, multiple linear regression which is optimized for forecasting period of 2018-2036 using 19902017 (Table 2). This study used the following data types: (i) EC and (ii) economic indicators GDP and POP in 1993-2017 (Fig. 2). NNs are used on forecasting problems characterized with unknown inputs and outputs. After training, various NN architectures, such as a multilayer perceptron (MLP) and a radial basis function networks (RBFNs) are used for EC forecasting [9].

In Thailand, EC and peak power demand have increased rate between $7.0-7.5 \%$ per annum from 1989-2008 [10]. EC will likely continue to increase in the future as well. Fig. 3 shows EC and peak power demand from 1969-2017. Conversely, EC and peak power demand slump as a consequence various economic crises in 1998-1999, 2008-2009, and 2011-2012. Electricity utility planning utilizes and identifies the importance of electricity forecasting [11]. In this research, NN architecture is used MLP by a feed-forward propagation training algorithm. The proposed NN for this study show the output as EC and peak demands from 2018-2036. 
Table 2. The historical data of influential input

\begin{tabular}{|c|c|c|c|c|c|c|c|c|c|}
\hline \multirow{2}{*}{ Year } & \multicolumn{6}{|c|}{ Power Generation Capacity by Fuel Type (GWh) } & \multirow{2}{*}{$\frac{\text { POP }}{\text { (Million) }}$} & \multirow{2}{*}{$\frac{\text { GDP }}{\text { (Billion) }}$} & \multirow{2}{*}{$\frac{\mathrm{EC}}{(\mathrm{GWh})}$} \\
\hline & HP & $\mathrm{TM}$ & $\mathrm{CC}$ & GT & DS & Total & & & \\
\hline 1990 & 4,858 & 31,259 & 4,888 & 1,444 & 21 & 43,189 & 55.84 & $3,373.5$ & 39,368 \\
\hline 1991 & 4,413 & 31,700 & 11,541 & 909 & 8 & 49,225 & 57.03 & $3,656.9$ & 44,773 \\
\hline 1992 & 4,506 & 36,688 & 13,345 & 945 & 9 & 56,007 & 57.62 & $3,994.5$ & 50,771 \\
\hline 1993 & 3,826 & 37,975 & 18,667 & 1,126 & 13 & 62,180 & 58.44 & $4,341.0$ & 56,558 \\
\hline 1994 & 3,431 & 39,194 & 25,084 & 1,085 & 9 & 69,651 & 59.24 & $4,688.2$ & 63,642 \\
\hline 1995 & 6,684 & 42,391 & 20,400 & 1,687 & 2 & 78,880 & 59.28 & $5,068.9$ & 72,779 \\
\hline 1996 & 7,233 & 45,310 & 19,204 & 2,704 & 4 & 85,924 & 59.90 & $5,355.4$ & 79,450 \\
\hline 1997 & 7,055 & 44,818 & 21,863 & 2,554 & 3 & 92,724 & 60.50 & $5,207.9$ & 85,896 \\
\hline 1998 & 5,881 & 42,147 & 24,323 & 1,566 & 4 & 92,134 & 61.20 & $4,810.3$ & 85,597 \\
\hline 1999 & 3,433 & 38,374 & 25,379 & 1,252 & 3 & 90,413 & 61.80 & $5,030.3$ & 84,512 \\
\hline 2000 & 5,296 & 36,151 & 25,556 & 1,153 & 2 & 96,780 & 61.88 & $5,254.4$ & 90,724 \\
\hline 2001 & 6,310 & 31,617 & 22,685 & 1,138 & 2 & 103,165 & 62.31 & $5,435.4$ & 97,412 \\
\hline 2002 & 6,480 & 30,127 & 23,529 & 1,117 & 5 & 108,389 & 62.80 & $5,769.6$ & 102,485 \\
\hline 2003 & 7,741 & 30,826 & 19,346 & 1,084 & 4 & 116,743 & 63.08 & $6,184.4$ & 110,675 \\
\hline 2004 & 5,915 & 31,538 & 20,652 & 1,090 & 2 & 125,318 & 61.97 & $6,573.3$ & 118,938 \\
\hline 2005 & 5,845 & 33,570 & 23,534 & 1,315 & 2 & 133,621 & 62.42 & $6,848.6$ & 127,025 \\
\hline 2006 & 7,950 & 33,648 & 25,137 & 1,088 & 1 & 142,004 & 62.83 & $7,188.8$ & 134,060 \\
\hline 2007 & 7,960 & 32,146 & 24,762 & 901 & 1 & 146,925 & 63.04 & $7,579.5$ & 139,445 \\
\hline 2008 & 6,950 & 29,128 & 27,209 & 675 & 2 & 148,266 & 63.39 & $7,710.3$ & 141,558 \\
\hline 2009 & 6,941 & 23,463 & 33,164 & 306 & 1 & 145,286 & 63.53 & $7,657.1$ & 141,692 \\
\hline 2010 & 5,325 & 27,289 & 38,338 & 275 & 3 & 160,189 & 63.88 & $8,232.4$ & 156,125 \\
\hline 2011 & 7,912 & 24,996 & 37,211 & 338 & 0.5 & 158,963 & 64.08 & $8,301.6$ & 155,207 \\
\hline 2012 & 8,408 & 26,168 & 42,551 & 370 & 0.4 & 173,250 & 64.46 & $8,902.8$ & 169,369 \\
\hline 2013 & 5,390 & 25,732 & 40,531 & 453 & 0.8 & 173,535 & 64.79 & $9,142.1$ & 169,530 \\
\hline 2014 & 5,141 & 24,764 & 43,052 & 370 & 1 & 177,580 & 65.12 & $9,232.1$ & 173,603 \\
\hline 2015 & 3,724 & 20,560 & 45,225 & 308 & 0.5 & 183,466 & 65.73 & $9,510.9$ & 179,537 \\
\hline 2016 & 3,521 & 20,296 & 43,679 & 261 & 0.5 & 188,999 & 65.93 & $9,823.1$ & 185,046 \\
\hline 2017 & 4,685 & 49,717 & 38,290 & 1,242 & 27 & 188,934 & 66.19 & $10,237.0$ & 185,130 \\
\hline
\end{tabular}

\subsubsection{Multiple linear regression model}

EC as it may be assessed with the mathematical, a linear combination of various independent variables because of characteristics of the regressions model, MLR technique. The regression model occurs when observational data are modeled with the least square function and is a linear combination of the parameters of the MLR model as follows in Eq. (1).

$$
y_{t}=a x_{1}+b x_{2}+c x_{3}+d x_{4}+e
$$

Where, $y_{t}$ is the dependent variable EC, $x_{1}, x_{2}, x_{3}$ and $x_{4}$ are the independent variable (POP, GDP,
IMP and EXP respectively), a, b, c and $d$ are the coefficients of regression model and e is a constant parameter of the regression model. In constant, the parameter represents unrecognized variation in the dependent variable and random variable. The POP, GDP, IMP, and EXP parameters are estimated to best fit of the data. The best fit is evaluated with the method of least squares regression.

\subsubsection{Neural networks model}

The NN method is used to forecast EC, where the outputs are unknown $[12,13]$. It is possible to become trapped in local minimal or to become subjective in selecting the NN model, architecture using the feed-forward propagation method as 
based on a gradient descent [14]. We normalized the input data for designing an $\mathrm{NN}$ [15] as follow:
Where, $n$ is number of data, $\bar{x}_{i}$ are normalized data and $x_{i}$ are actual values of historical data.

$$
\bar{x}_{i}=\frac{x_{i}-\min \left(x_{i}\right)}{\max \left(x_{i}\right)-\min \left(x_{i}\right)}, i=1,2, \ldots, n
$$

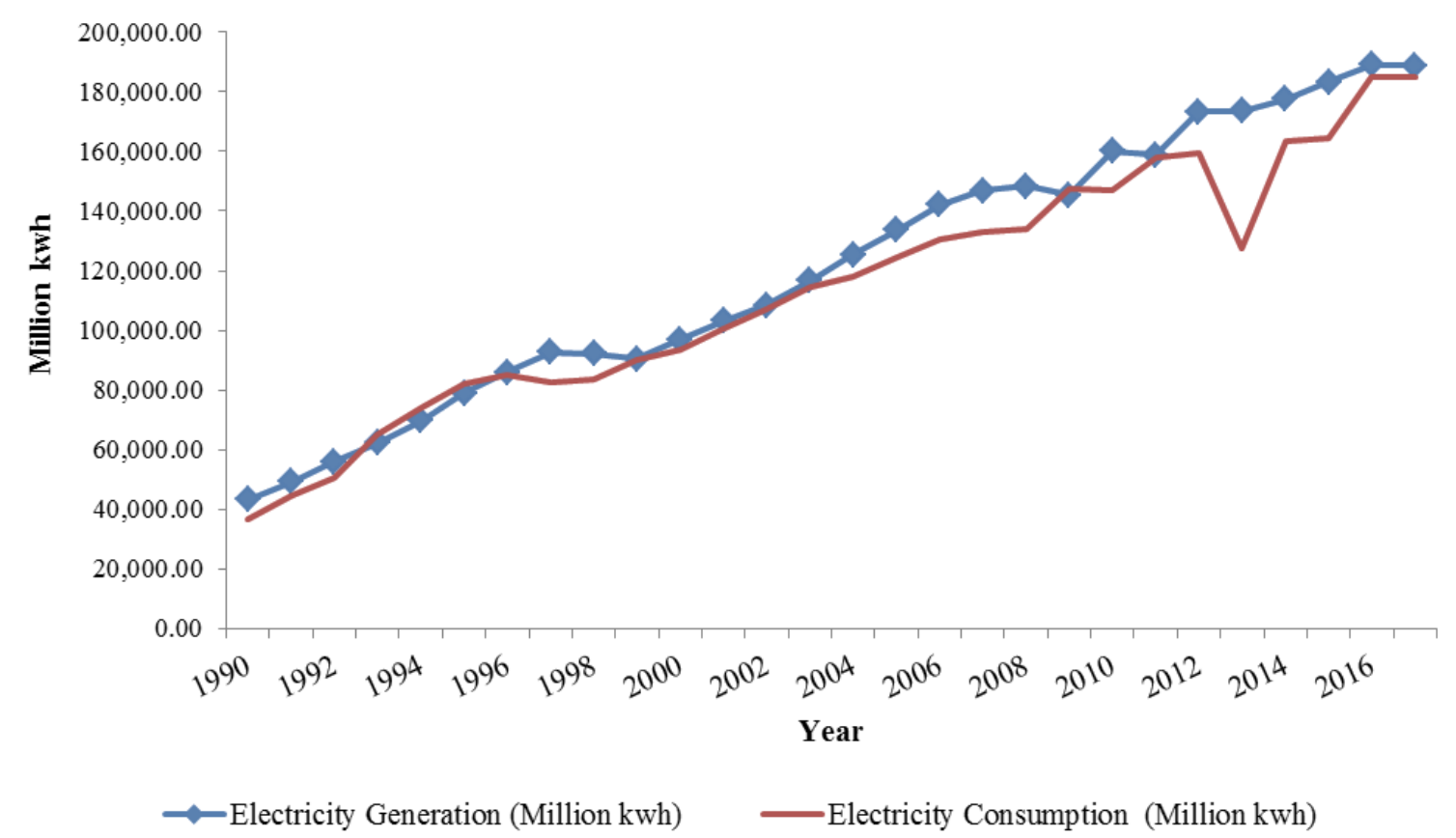

(a)

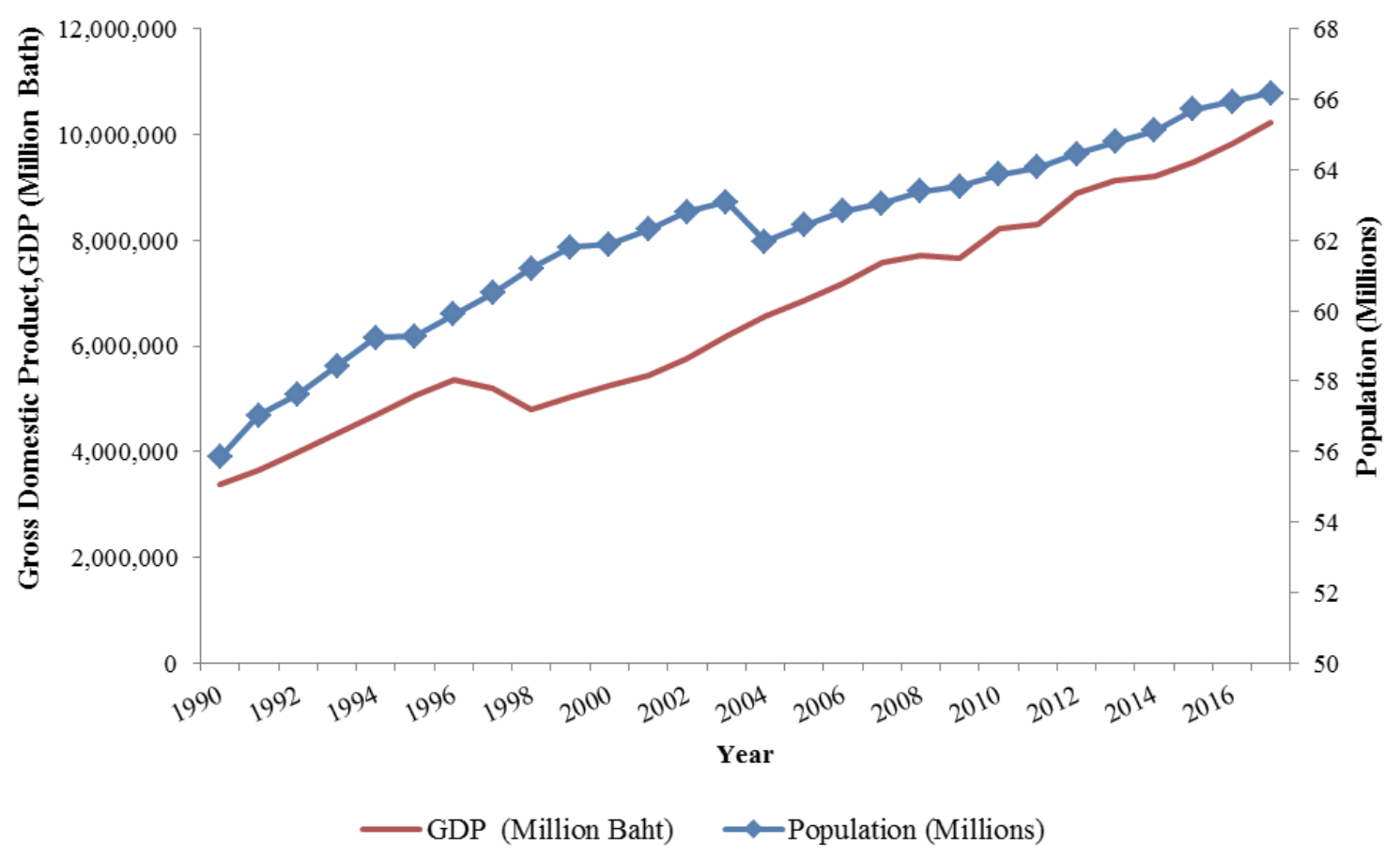

(b)

Figure. 2 The electricity consumption and economic data:

(a) Electricity Consumption vs. Electricity Generation and (b) Gross Domestic Product vs. Population 


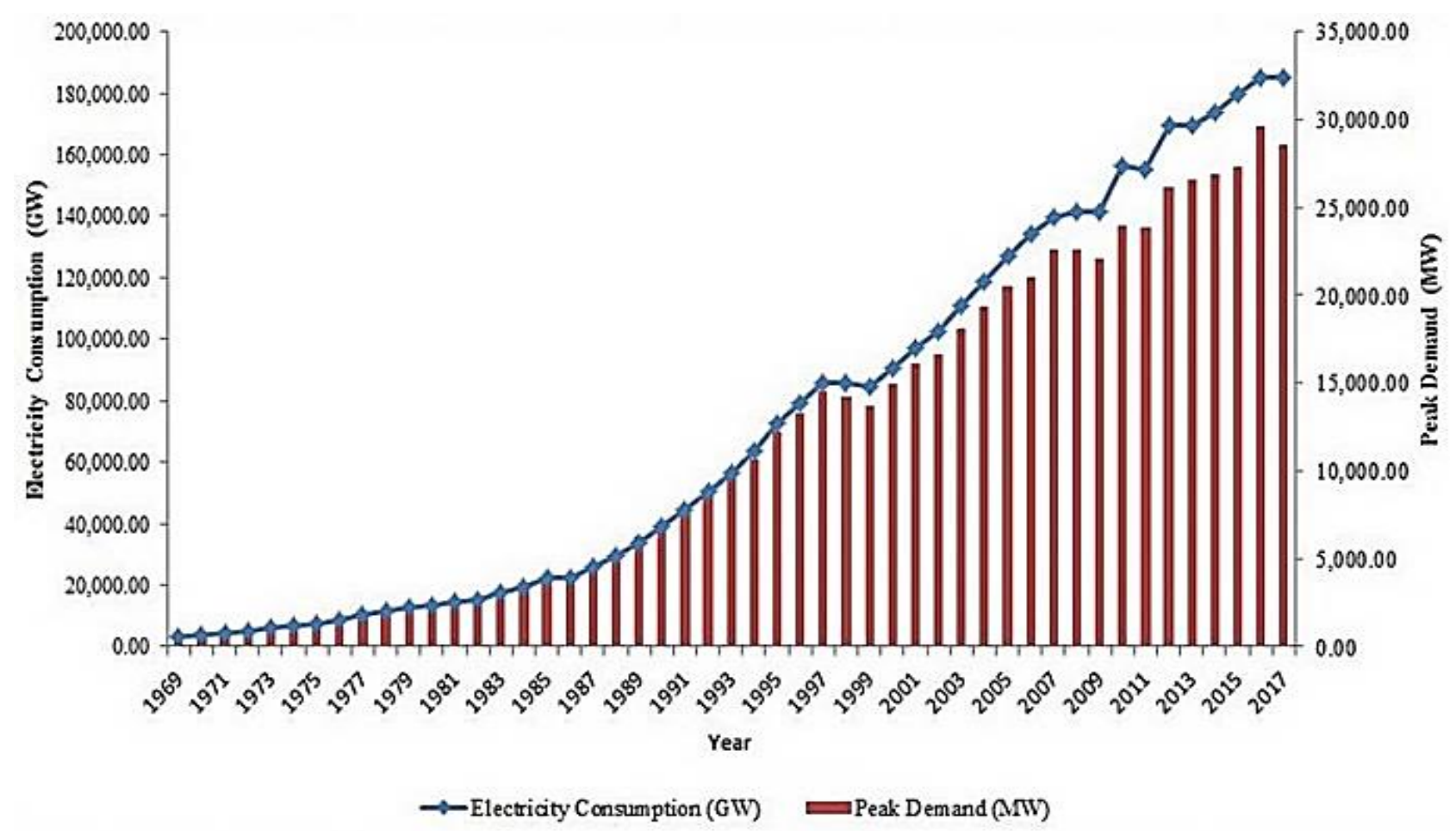

Figure.3 Peak power demand and EC in Thailand from 1969 - 2017

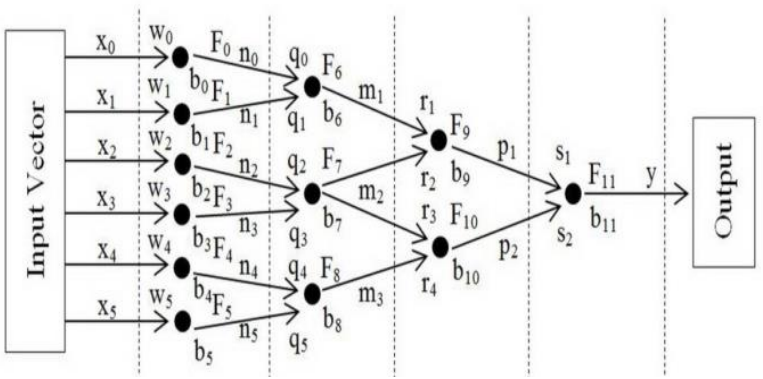

(a)

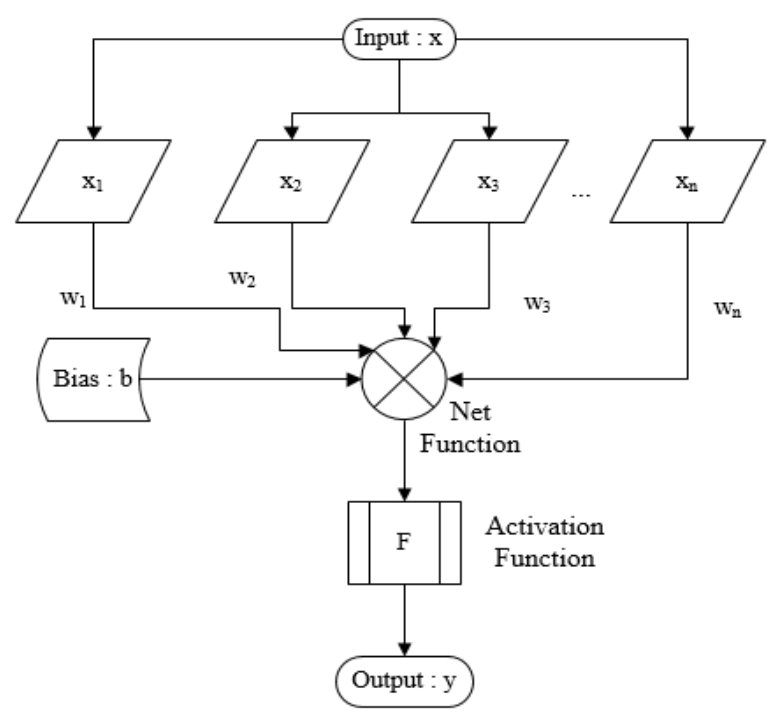

(b)

Figure.4 Feed-forward artificial neural network:

(a) NN structure, (b) NN process
Feed-Forward artificial neural networks (FANNs) have only one condition which is unidirectional information that flows from input to output. In the feed-forward process, the information is only moving in the forward direction from the input nodes $x$ passing through the hidden nodes to the output nodes $y$ with no looping in the network. The model uses a simple sigmoid activation function $(f)$ to produce output values (y). The multi-layer FANNs (Fig. 4) are corresponding analytical description with sets of Eqs. (3), (4) (5), and (7) driven to generally long mathematical descriptions where solving by hand is not feasible. Computers and specialized software are required to build, describe and optimize any types of $\mathrm{NN}$.

\section{Definition}

$x, n, m, p, y$ are signals $w, q, r, s$ are weights, $F$ is transfer function and $b$ is biases.

The historical data are $\mathrm{x}_{1}$ : EC, $\mathrm{x}_{2}$ : GDP, $\mathrm{x}_{3}$ : POP, $\mathrm{x}_{4}$ : IMP, $\mathrm{x}_{5}$ : EXP, weights and biases are coefficient.

The NN uses a tanh function that is not bounded or continuously differentiable. This function is piece-wise linear and saturates at 0 whenever the input $\mathrm{x}$ is less than 0 . The equation indicates that a nonlinear activation function $f$ takes a weighted sum of input $x$ values and returns a value for $F_{n}^{l}$ as: 


$$
\begin{aligned}
& F_{j}^{l}=f\left(\sum_{i=1}^{k} w_{i j}^{l} x_{i}\right) \\
& n_{0}=F_{0}\left(w_{0} x_{0}+b_{0}\right) \\
& n_{1}=F_{1}\left(w_{1} x_{1}+b_{1}\right) \\
& n_{2}=F_{2}\left(w_{2} x_{2}+b_{2}\right) \\
& n_{3}=F_{3}\left(w_{3} x_{3}+b_{3}\right) \\
& n_{4}=F_{4}\left(w_{4} x_{4}+b_{4}\right) \\
& n_{5}=F_{5}\left(w_{5} x_{5}+b_{5}\right)
\end{aligned}
$$

$$
y=F_{11}\left(s_{1} p_{1}+s_{2} p_{2}+b_{11}\right)
$$$$
y=F_{11}\left(s _ { 1 } \left(F _ { 9 } \left(r _ { 1 } \left(F _ { 6 } \left(q _ { 0 } \left(F_{0}\left(w_{0} x_{0}+b_{0}\right)+\right.\right.\right.\right.\right.\right.
$$$$
q_{1}\left(F_{1}\left(w_{1} x_{1}+b_{1}\right)+b_{6}\right)+
$$$$
r_{2}\left(F _ { 7 } \left(q _ { 2 } \left(F_{2}\left(w_{2} x_{2}+b_{2}\right)+q_{3}\left(F _ { 3 } \left(w_{3} x_{3}+\right.\right.\right.\right.\right.
$$$$
\left.\left.\left.b_{3}\right)+b_{7}\right)+b_{9}\right)+s_{2}\left(F _ { 1 0 } \left(r _ { 3 } \left(F _ { 7 } \left(q _ { 2 } \left(F _ { 2 } \left(w_{2} x_{2}+\right.\right.\right.\right.\right.\right.
$$$$
\left.b_{2}\right)+q_{3}\left(F_{3}\left(w_{3} x_{3}+b_{3}\right)+b_{7}\right)+
$$$$
r_{4}\left(F _ { 8 } \left(q _ { 4 } \left(F_{4}\left(w_{4} x_{4}+b_{4}\right)+q_{5}\left(F _ { 5 } \left(w_{5} x_{5}+\right.\right.\right.\right.\right.
$$$$
\left.\left.\left.\left.b_{5}\right)+b_{8}\right)+b_{10}\right)+b_{11}\right)
$$

$$
w^{n}=w^{o}-\eta \nabla_{w} J\left(w^{o} ; x^{k} ; y^{k}\right)
$$

Where, $F_{j}^{l}$ is the $j^{\text {th }}$ hidden node in layer $l$, $w_{i j}^{l}$ is the weight between node $i$ in layer $(l-1)$ and node $j$ in layer $l, F$ is activation function, $w^{n}$, $w^{o}$ are updated weight value and old weight value respectively, $J$ is gradient value, $\eta$ is learning rate and $x^{k}, y^{k}$ are pair of a training sample at the $k^{\text {th }}$ iteration.

The error during the $\mathrm{NN}$ design phase is $\mathrm{EC}_{\mathrm{MAPE}}$ which serves as the fitness function that must be minimized as:

$$
\min E C_{M A P E}=\frac{1}{n} \sum_{i=1}^{n}\left|\frac{A_{i}-F_{i}}{A_{i}}\right| \times 100
$$

Where, $A_{i}$ and $F_{i}$ are the target and the forecasted EC value at period $i$, respectively.

The uncertain factors in the power capacity forecast include electricity demand which higher than estimated, fluctuating renewable energy sources, power purchasing and relying on neighboring countries, high consumption of natural gas in power generation and rescheduling of large power plants' commercial operation dates.

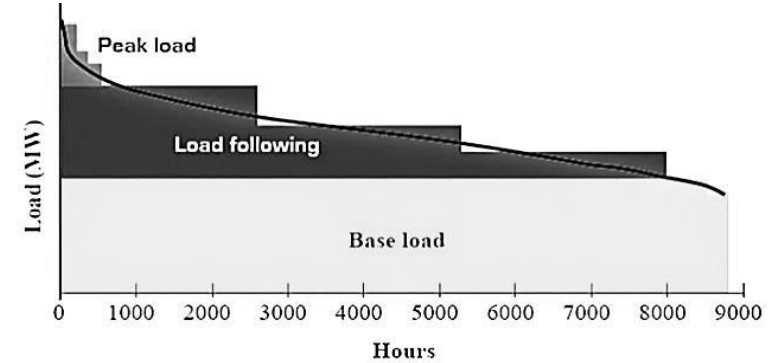

(a)

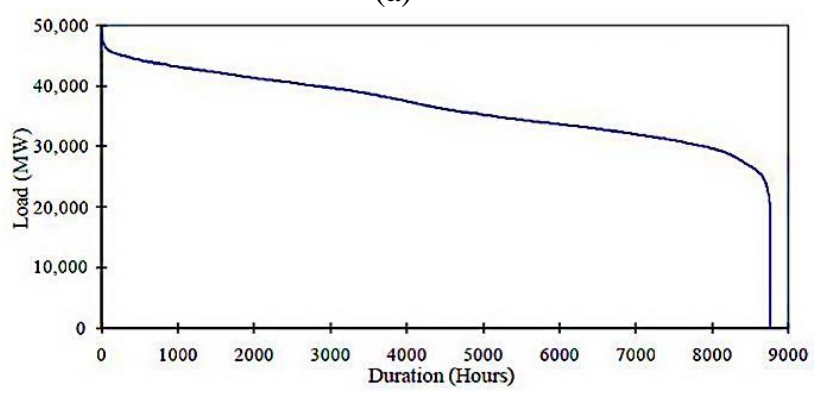

(b)

Figure.5 Load duration curve: (a) basic curve and (b) load duration curve in demand forecasted with $\mathrm{NN}$ in Thailand 2036

Nevertheless, an appropriate level of generation capacity has been set to be not less than $15 \%$ of peak demand to ensure the security of electricity supply and to cope with uncertainties.

\subsubsection{Load model}

First, we investigated data using an annual hourly load curve. Then used the energy load duration curve (Fig. 5) to develop the generation system model to obtain the reliability indices, i.e., conventional unsupplied resource of energy.

Electricity demand is a single product with demand levels varying over time. Electricity producers use a "load-curve" to describe demand over time increasing, forecasted with NN shown in Fig. 6. The problem in concern is the long-term investments, so for the study we considered the load curve as having occurred over a year.

The electricity demand under uncertainty is the possibility of the electric load to increase or decrease from the baseline of the fixed load. The method uses the distribution to illustrate forecasted peak loads. We divided the distribution into intervals. The normal distribution was divided into seven parts with a 5\% standard deviation (SD) of intervals for the purposes of this study. Reliability for power system uses the load forecast uncertainty model as follows:

1. Load-curve (LC) is picked in the SD against the mean of peak level. The LC is generated with accumulate the peak electricity demand value in uncertainty. The value is then 
combined to the peak value which represents expand; or conversely, subtracted from the peak value to represent a decline in peak uncertainty.

2. LC is probability that obtains the weighted values for particular level.

3. The corresponding reliability index of load forecasted is the sum of all weighted loads.

Each unit is assumed to generate electricity from an adequate fossil resource. However, some power generating units, example hydro resources, are an energy-limited type, because the amount of water varies over time. As such, hydro resources are used as peak shaving units, i.e. leaving the remaining demand to be supplied by other types of units. Fig. 6 and Table 3 show the characteristics for demand as probability distribution.

\subsection{Stochastic optimization model}

Those responsibilities are in charge of the decisions for allocating electricity generation patterns and any capacity expansions with minimal system costs over a long-term planning horizon [16]. To effectively manage energy resources and facilities, the components are integrated into the modeling framework. The following are the challenges for the planning: (i) identifying optimal capacity-expansion schemes; (ii) maximizing hydropower generation; (iii) reflecting on the stochastic features for any uncertain parameters such as demands, allowable capacities of water for hydropower plants; (iv) analyzing any tradeoffs between efficiency and reliability; and (v) minimizing environment harm.

Table 4 shows the capacity for Thailand's power system. Fig. 8 shows the electric power plants diagram by technology. Power plants are rated in accordance with production capacity as measured in megawatts (MW).

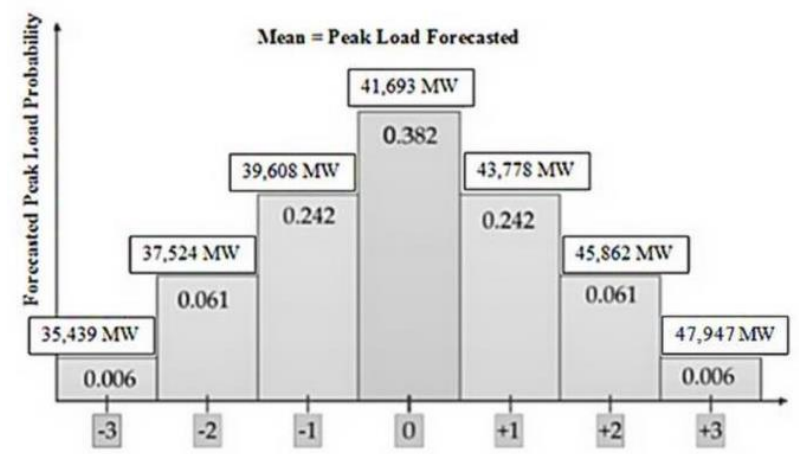

Figure.6 Probability distribution approximation
Table 5 shows investments and operational costs for each plant type.

Table 3. The reliability indices consolidate load forecast uncertainty

\begin{tabular}{|c|c|c|c|c|}
\hline SD & Load (MW) & RI & Prob. & Weighted \\
\hline-3 & $\begin{array}{l}41693-(15 \% \times \\
41693)=35439\end{array}$ & $\mathrm{i}$ & 0.006 & $\mathrm{i} \times 0.006$ \\
\hline-2 & $\begin{array}{l}41693-(10 \% \times \\
41693)=37524\end{array}$ & ii & 0.061 & ii $\times 0.061$ \\
\hline-1 & $\begin{array}{l}41693-(5 \% \times \\
41693)=39608\end{array}$ & iii & 0.242 & iii $\times 0.242$ \\
\hline 0 & $\begin{array}{l}41693-(0 \% \times \\
41693)=41693\end{array}$ & iv & 0.382 & $\mathrm{iv} \times 0.382$ \\
\hline+1 & $\begin{array}{l}41693+(5 \% \times \\
41693)=43778\end{array}$ & $\mathrm{~V}$ & 0.242 & $\mathrm{v} \times 0.242$ \\
\hline+2 & $\begin{array}{l}41693+(10 \% \times \\
41693)=45862\end{array}$ & vi & 0.061 & vi $\times 0.061$ \\
\hline+3 & $\begin{array}{l}41693+(15 \% \times \\
41693)=47947\end{array}$ & vii & 0.006 & vii $\times 0.006$ \\
\hline \multicolumn{5}{|c|}{$\begin{aligned} \text { Reliability } & =\sum \text { weighted of reliability index } \\
(\mathrm{RI}) & =\mathrm{i} \times 0.006+\mathrm{ii} \times 0.061+\mathrm{iii} \times 0.242+\mathrm{iv} \times \\
& 0.382+\mathrm{v} \times 0.242+\mathrm{vi} \times 0.061+\mathrm{vii} \times 0.006\end{aligned}$} \\
\hline
\end{tabular}

Table 4. The power plants capacity in Thailand.

\begin{tabular}{|c|c|c|r|}
\hline $\begin{array}{c}\text { Power } \\
\text { Plant }\end{array}$ & $\begin{array}{c}\text { Number of } \\
\text { Power Plant }\end{array}$ & $\begin{array}{c}\text { Capacity } \\
\text { Factor }\end{array}$ & $\begin{array}{c}\text { Total Capacity } \\
\text { (MW) }\end{array}$ \\
\hline (TM) & 3 & $0.8-0.9$ & 3,647 \\
\hline (CC) & 6 & $0.8-0.9$ & 8,896 \\
\hline (GT) & 1 & $0.8-0.9$ & 500 \\
\hline (HP) & 27 & $0.2-0.5$ & 2,952 \\
\hline (DS) & 4 & $0.8-0.9$ & 30 \\
\hline (RW) & 9 & $0.15-0.25$ & 45 \\
\hline
\end{tabular}

Table 5. The construction and operation cost with fuel.

\begin{tabular}{|c|c|r|}
\hline $\begin{array}{c}\text { Energy } \\
\text { Types }\end{array}$ & $\begin{array}{c}\text { Construction } \\
\text { (Bath / kw) }\end{array}$ & $\begin{array}{c}\text { Operation } \\
\text { (Bath/kw /Year) }\end{array}$ \\
\hline (CC) & 24,718 & 7,500 \\
\hline (TM) & 52,700 & 6,760 \\
\hline (GT) & 14,858 & 10,125 \\
\hline (HP) & & \\
Large > 50 MW & 132,000 & 1,980 \\
Small < 50 MW & 148,500 & 2,150 \\
\hline Nuclear & 104,959 & 14,560 \\
\hline
\end{tabular}

Table 6. The environmental, tax and cost of technological

\begin{tabular}{|l|r|r|r|r|r|r|}
\hline $\begin{array}{l}\text { Energy } \\
\text { Types }\end{array}$ & $\mathrm{CO}_{2}$ & $\mathrm{NO}_{x}$ & $\mathrm{SO}_{2}$ & $\mathrm{TSP}$ & $\begin{array}{c}\text { Tax } \\
\text { Fees }\end{array}$ & Cost \\
\hline $\mathrm{HP}$ & 15 & 0.02 & 0.01 & 0.01 & - & 2.92 \\
\hline Coal & 960 & 3.79 & 3.76 & 0.33 & 0.42 & 2.93 \\
\hline $\begin{array}{l}\text { Natural } \\
\text { Gas }\end{array}$ & 512 & 1.25 & 0.31 & 0.01 & 0.23 & 3.10 \\
\hline Nuclear & 170 & 0.00 & 0.00 & 0.00 & - & 3.60 \\
\hline RW & 30 & 0.01 & 0.02 & 0.02 & - & 4.19 \\
\hline Oil & 770 & 2.90 & 4.90 & 0.25 & - & 4.93 \\
\hline Diesel & 650 & 2.90 & 1.29 & 0.25 & - & 4.93 \\
\hline
\end{tabular}


Table 7. The pollutant of emission used electricity generation each technology

\begin{tabular}{|c|c|c|c|c|c|c|c|c|c|c|}
\hline \multirow{2}{*}{ Year } & \multicolumn{8}{|c|}{$\begin{array}{l}\text { Pollutant Emission } \\
\text { (Ton/Year) }\end{array}$} & \multicolumn{2}{|c|}{$\begin{array}{c}\text { Electricity } \\
\text { Generation } \\
(\mathrm{GWh})\end{array}$} \\
\hline & $\begin{array}{c}\text { Natural } \\
\text { Gas }\end{array}$ & Oil Fuel & Diesel & $\begin{array}{c}\text { Coal } \\
\text { Lignite }\end{array}$ & $\begin{array}{l}\mathrm{GHG} \\
\left(\mathrm{CO}_{2}\right)\end{array}$ & $\mathrm{NO}_{\mathrm{x}}$ & $\mathrm{SO}_{2}$ & TSP & $\begin{array}{c}\text { Fossil } \\
\text { Fuel }\end{array}$ & RW \\
\hline 2015 & $23,412,473$ & 546,719 & 34,544 & $15,322,740$ & $39,316,476$ & 79,151 & 28,732 & 1,845 & 66,093 & 3,745 \\
\hline 2016 & $21,228,208$ & 226,962 & 32,254 & $17,748,799$ & $38,836,323$ & 73,613 & 26,722 & 1,736 & 64,237 & 3,528 \\
\hline 2017 & $17,494,788$ & 77,127 & 115,484 & $16,811,959$ & $34,499,359$ & 59,319 & 21,778 & 1,713 & 56,124 & 4,667 \\
\hline
\end{tabular}

Table 6 shows the factors regarding preventing harm to the environment for each type of plant, additionally the costs of electricity as Bath/kwh.

Table 7 shows the historical data used for testing from 2015-2017. The operational costs of hydropower plants are the lowest because there is a minimum requirement in fuel consumption and least environmental harm emission.

The operational costs for nuclear based power plants are unable to be used to estimate costs because of nuclear waste products will be around well after the plant has closed however; data might be easily included for this task.

Definition GHG: greenhouse gases $\left(\mathrm{CO}_{2}\right)$ and TSP: total suspended particulate. In $\mathrm{CO} 2, \mathrm{NOx}$, SO2 and TSP: g/kwh and tax fee and cost: bath/kwh.

\subsubsection{A multi-stage stochastic model}

The following elements justify the use of a dynamic multi-stage method for the electricity generation planning to investment:

1. The total costs in long-term

2. The load curve in long-term

3. New technologies

4. Presently available equipment will become obsolete

5. The emission environment cost from power generation

The equipment costs are influenced by changing technologies and growing fuel costs and emission tax fees. The most important aspect as demand grows is the total energy demanded and peak-levels. These determine the total capacity available to meet power demands. As new technologies appear, the specialized and commercial accomplishment of the study and improvement depends on past decisions with the technical and lifetime value of any equipment. We developed a multiple stage stochastic optimization model based on [17, 18] with advantage environments effects of cost and LC with $\mathrm{NN}$ forecasted in electricity consumption demand as illustrated below:

$$
\min \mathrm{E}_{\xi} \sum_{t=1}^{N}\left(\sum_{p=1}^{n} c_{p}^{t} \delta_{p}^{t}+\sum_{p=1}^{n} \sum_{j=1}^{k} q_{p}^{t} T_{j}^{t} y_{p j}^{t} e_{p}^{t}\right)
$$

$$
\begin{aligned}
& \text { Subject to } \\
& \sum_{p=1}^{n} c_{p}^{t} \delta_{p}^{t} \leq b_{p}^{t} \\
& \delta_{p}^{t}=\delta_{p}^{t-1}+x_{p}^{t}-x_{p}^{t-L p} \\
& p=1, \ldots, n ; t=1, \ldots, N \\
& \sum_{p=1}^{n} y_{p j}^{t} \geq d_{j}^{t} ; j=1, \ldots, k ; t=1, \ldots, N \\
& \sum_{p=1}^{n} y_{p j}^{t} \geq w_{j}^{t} ; j=1, \ldots, k ; t=1, \ldots, N \\
& \sum_{j=1}^{k} y_{p j}^{t} \leq a_{p}\left(g_{p}^{t}+\delta_{p}^{t-\Delta_{p}}\right) \\
& p=1, \ldots, n ; t=1, \ldots, N \\
& a_{n}\left(g_{n}^{t}+\delta_{n}^{t-1}+x_{n}^{t}\right) \\
& \quad \geq D_{m}^{t}-\sum_{p=1}^{n-1} a_{p}\left(g_{p}^{t}+\delta_{p}^{t-\Delta_{p}}\right) \\
& p=1, \ldots, n ; t=1, \ldots, N \\
& \delta, x, y \geq 0 \\
& \delta_{p}^{t}=\delta_{p}^{t-1}+x_{p}^{t}
\end{aligned}
$$

Definition The following multi-stage stochastic model can be proposed. Let as:

$$
\begin{aligned}
& p \quad=\text { power plant type } \\
& j \quad=\text { resource supply fuel } \\
& n \text { = number of technologies available for power } \\
& \text { plant } \\
& m \text { = demand of peak load forecasted with load } \\
& \text { curve } \\
& x_{p}^{t}=\text { new capacity made available for } \\
& \text { technology } p \text { at time } \mathrm{t} \\
& \delta_{p}^{t}=\text { total capacity of } \mathrm{i} \text { available at time } \mathrm{t}
\end{aligned}
$$


$a_{p} \quad=$ availability factor of $p$

$L_{p}=$ life-time of $p$

$g_{p}^{t}=$ existing capacity of $p$ at time $\mathrm{t}$, decided before

$\mathrm{t}=1$

$d_{j}^{t}=$ maximal demanded resource at time $\mathrm{t}$

$T_{j}^{t}=$ duration of mode $p$ at time $\mathrm{t}$

$y_{p} j^{t}=$ capacity of $p$ effectively used at time $\mathrm{t}$

$c_{p}^{t}=$ unit investment cost for $p$ at time $\mathrm{t}$ (on a yearly equivalent basis)

$q_{p}^{t}=$ unit production cost for $p$ at time $\mathrm{t}$

$\xi_{t}=$ represents the random variable at time $\mathrm{t}$

$e_{p}^{t}=$ unit emission tax fees cost for $p$ at time $\mathrm{t}$ (only coal/lignite and natural gas fuel)

$w_{j}^{t}=$ the limitation of fresh water of mode $p$ at time $\mathrm{t}$

$b_{p}^{t}=$ the upper bound budget for construction cost of mode $p$ at time $\mathrm{t}$

$D_{m}^{t}=$ the power demanded in load curve with $\mathrm{NN}$ forecasted at time $\mathrm{t}$

The stochastic optimization model (SOM) finds the best structure for power plant capacity required to satisfy regional power demands as forecasted by vector $x$. The objective function minimizes the expected value of system costs and is related to the following: (i) supply costs, energy resource; (ii) variable operational costs regarding power conversion; (iii) investment construction costs expand capacity; and (iv) shouldering environmental emissions. We classified the decision variables into the following categories: (i) continuous variables - coal and natural gas production, conversion technologies capacity, and electricity generation amounts; and (ii) generation variables if capacity expansion is necessary.

\subsection{Implementation to power generation planning}

Over 2018-2036, the electricity demand is expected to increase $2.7 \%$ per year and reach 49,655 MW and expect the stochastic model plan to save 89,672 million units, which will make the

Table 8 . Thailand's power systems capacity

\begin{tabular}{|c|r|r|}
\hline $\begin{array}{c}\text { Power } \\
\text { generation }\end{array}$ & $\begin{array}{c}\text { Capacity } \\
(\mathrm{MW})\end{array}$ & $\begin{array}{c}\text { Percentage } \\
(\%)\end{array}$ \\
\hline CC & 21,145 & 56.2 \\
\hline RW & 8,476 & 22.5 \\
\hline TM (Thermal) & 7,538 & 20.0 \\
\hline EGAT-TNB & 300 & 0.8 \\
\hline GT and DS & 153 & 0.5 \\
\hline Total & 37,612 & 100.0 \\
\hline
\end{tabular}

total contracted capacity to be at $70,335 \mathrm{MW}$ by the end of 2036.

The stochastic model is summed up best as follows in 2036. Fig. 7 is the flowchart for longterm EC modeling forecasting and stochastic optimization modeling while considering various input types. Thailand's power systems capacity is as follows shown in Table $8-9$.

\section{Results}

The EC forecasting and stochastic optimization models for long-term planning focus on the power development plan 2018-2036 in Thailand, (i) Security: meeting increasing power demands in

Table 9. Thailand producer's power systems capacity

\begin{tabular}{|c|r|r|}
\hline $\begin{array}{c}\text { Power } \\
\text { generation }\end{array}$ & $\begin{array}{c}\text { Capacity } \\
(\mathrm{MW})\end{array}$ & $\begin{array}{c}\text { Percentage } \\
(\%)\end{array}$ \\
\hline EGAT & 15,482 & 41.2 \\
\hline IPP $_{\mathrm{s}}$ & 13,167 & 35.0 \\
\hline SPP $_{\mathrm{s}}$ & 4,530 & 12.0 \\
\hline VSPP $_{\mathrm{s}}$ & 2,029 & 5.4 \\
\hline Import & 2,404 & 6.4 \\
\hline Total & 37,612 & 100.0 \\
\hline
\end{tabular}

Table 10. The generating capacity in expansion planning during $2018-2036$

\begin{tabular}{|c|c|c|c|}
\hline $\begin{array}{c}\text { Power Plant } \\
\text { Types }\end{array}$ & $\begin{array}{c}2017 \\
(\%)\end{array}$ & $\begin{array}{c}2026 \\
(\%)\end{array}$ & $\begin{array}{c}2036 \\
(\%)\end{array}$ \\
\hline Import \& Hydropower & 7 & 12 & 15 \\
\hline Coal / Lignite & 20 & 22 & 24 \\
\hline Natural Gas (LNG) & 64 & 50 & 30 \\
\hline Renewable & 8 & 15 & 25 \\
\hline Diesel / Oil Fuel & 1 & 1 & 1 \\
\hline Nuclear & - & - & 5 \\
\hline
\end{tabular}

Table 11 . The summary of generating capacity in expansion planning classify by technology

\begin{tabular}{|l|r|r|r|r|}
\hline $\begin{array}{c}\text { Power Plant Type } \\
\text { (MWh) }\end{array}$ & 2017 & \multicolumn{1}{c|}{$\begin{array}{c}2018 \\
-\end{array}$} & \multicolumn{1}{c|}{$\begin{array}{c}2027 \\
-\end{array}$} & Total \\
\hline Renewable & 8,746 & 15,500 & 9,600 & 25,100 \\
-Domestic \& HP & 3,500 & 9,100 & 5,000 & 14,100 \\
-Import neighbor & 3,246 & 5,500 & 4,000 & 9,500 \\
-Buy in domestic & 2,000 & 900 & 600 & 1,500 \\
\hline Combined Cycle & 21,145 & 15,500 & 3,500 & 19,000 \\
-Natural Gas & 8,896 & 14,500 & 3,000 & 17,500 \\
-Buy in domestic & 12,249 & 1,000 & 500 & 1,500 \\
\hline Thermal & 7,538 & 5,500 & 4,700 & 10,200 \\
-Coal / Lignite & 3,647 & 4,000 & 3,400 & 7,400 \\
-Buy in domestic & 3,591 & 700 & 600 & 1,300 \\
-Import neighbor & 300 & 800 & 700 & 1,500 \\
\hline Other & 153 & 230 & 1,070 & 1,300 \\
-Gas turbine & 123 & 200 & 1,050 & 1,250 \\
-Diesel / Oil & 30 & 30 & 20 & 50 \\
\hline Nuclear & - & - & 2,000 & 2,000 \\
\hline Total expansion & 37,582 & 36,730 & 20,870 & 57,600 \\
\hline
\end{tabular}


Table 12. The forecasted results of the MLR and NN model

\begin{tabular}{|c|c|c|c|}
\hline \multirow[t]{2}{*}{ Year } & \multicolumn{3}{|c|}{$\begin{array}{l}\text { Electricity Generation, Electricity Demand } \\
\text { and Peak Load (GWh) }\end{array}$} \\
\hline & Generation & Consumption & Peak Load \\
\hline 1990 & 44,765 & 39,369 & 7,221 \\
\hline 1991 & 50,713 & 44,773 & 8,045 \\
\hline 1992 & 57,509 & 50,771 & 8,904 \\
\hline 1993 & 63,982 & 56,558 & 9,839 \\
\hline 1994 & 71,973 & 63,642 & 11,064 \\
\hline 1995 & 80,436 & 72,780 & 12,268 \\
\hline 1996 & 87,797 & 79,451 & 13,311 \\
\hline 1997 & 93,407 & 85,897 & 14,506 \\
\hline 1998 & 91,156 & 85,598 & 14,180 \\
\hline 1999 & 91,414 & 84,512 & 13,712 \\
\hline 2000 & 98,487 & 90,724 & 14,918 \\
\hline 2001 & 103,856 & 97,412 & 16,126 \\
\hline 2002 & 111,256 & 102,486 & 16,681 \\
\hline 2003 & 117,290 & 110,676 & 18,121 \\
\hline 2004 & 121,534 & 118,939 & 19,326 \\
\hline 2005 & 134,798 & 127,025 & 20,538 \\
\hline 2006 & 141,919 & 134,061 & 21,064 \\
\hline 2007 & 147,026 & 139,446 & 22,586 \\
\hline 2008 & 148,264 & 141,559 & 22,568 \\
\hline 2009 & 145,159 & 141,693 & 22,045 \\
\hline 2010 & 160,152 & 156,125 & 24,010 \\
\hline 2011 & 158,937 & 155,207 & 23,900 \\
\hline 2012 & 173,320 & 169,370 & 26,121 \\
\hline 2013 & 173,377 & 169,530 & 26,598 \\
\hline 2014 & 177,261 & 173,604 & 26,942 \\
\hline Testing & Actual & MLR & $\mathrm{NN}$ \\
\hline Model & $\begin{array}{l}\text { Testing } \\
\text { Value }\end{array}$ & $\begin{array}{l}\text { Demand \& } \\
\text { Peak load }\end{array}$ & $\begin{array}{l}\text { Demand \& } \\
\text { Peak load }\end{array}$ \\
\hline 2015 & 179,537 & 179,137 & 179,456 \\
\hline & 27,346 & 27,015 & 27,340 \\
\hline 2016 & 185,047 & 184,747 & 184,850 \\
\hline & 29,619 & 28,385 & 28,590 \\
\hline 2017 & 185,131 & 184,831 & 185,355 \\
\hline & 28,578 & 29,075 & 28,940 \\
\hline \multirow{3}{*}{ Error } & R Square & 0.95 & 0.98 \\
\hline & MAPE (\%) & 1.87 & 1.15 \\
\hline & RMSE & 2,685 & 2,077 \\
\hline Time & PDP & MLR & $\mathrm{NN}$ \\
\hline Periods & Forecasted & Forecasted & Forecasted \\
\hline \multirow[t]{2}{*}{2018} & 200,500 & 210,500 & 205,150 \\
\hline & 28,338 & 29,535 & 29,215 \\
\hline \multirow[t]{2}{*}{2022} & 248,500 & 236,001 & 240,395 \\
\hline & 36,776 & 37,350 & 36,850 \\
\hline \multirow[t]{2}{*}{2026} & 303,137 & 270,816 & 281,596 \\
\hline & 40,791 & 41,135 & 41,050 \\
\hline \multirow[t]{2}{*}{2030} & 341,032 & 314,385 & 323,885 \\
\hline & 44,424 & 45,050 & 44,750 \\
\hline \multirow[t]{2}{*}{2036} & 393,335 & 365,050 & 379,850 \\
\hline & 49,655 & 50,015 & 49,985 \\
\hline
\end{tabular}

concerned with the economic and Nation Development as well as considering fuel diversification to dependency on any one power - source; (ii) Economic: developing appropriate costs for power generation to engender long-term economic competitiveness and energy efficiency; and (iii) Ecological: the reduction of environmental seeking lessened $\mathrm{CO}_{2}$ in electricity generation process.

In 2036, the demand capacity will need to be $70,335 \mathrm{MW}$ and will have a present capacity of $37,612 \mathrm{MW}$, a further capacity of 57,459 MW, and a removed capacity (2018-2036) as 24,736 MW. These are shown as follows:

-Generating and retired capacity between 2018 until 2036

-Present capacity 37,612 MW (end of 2017)

-New capacity more over 57,459 MW

-Removed capacity 24,736 MW

-Further demand capacity 70,335 MW in 2036

The results from stochastic optimized model and forecasting in long-term are power plant technology installed and environmental affect cost.

In the end, we will have summary of generating capacity expansion planning classify by technology in time period shown in Table 10 and 11. The forecasted results with the MLR and NN models in electricity consumption are shown in Table 12. The production of renewable energy will be used instead of oil and gas production to consider the impact on the environment and cost.

\section{Conclusion}

The following targets for 2036's installed capacity: 57,600 MW for renewable; and wind, solar, and small-hydro were set at 3,000 MW, 6,000 MW, and 5,100 MW, respectively. The current status of renewable energy sources in Thailand makes these goals ambitious. The installed capacity for wind power tripled from 2014 to 2017 to $627.82 \mathrm{MW}$. The capacity for solar power nearly doubled to 2,692.26 MW of 2014-2017. Thailand is halfway to its 6,000 MW goal for installed solar capacity by 2036 . Both the demand and supply of solar power are growing and the future will require upward revisions. The pivot to renewable power sources will satisfy the stochastic optimization model. Thailand has shown great potential for continuing growth of the renewable energy sector.

Based on the limitations of the long-term electricity generation planning established by the government, the current study produced a power generation system operation plan model that can calculate realistic operation and construction costs, moreover it can be solve the optimization for generation in best value. 
In the future, if any researchers want to use the proposed stochastic model, it must be consideration factors in the topography that affects the production of renewable energy. A constrain will be adjust according to the efficiency of electricity production in each country; hydro power, solar and wind power plant. For sustainability, enough production capacity of electrical should be increased without the need to purchase energy from different countries, will be decrease a risk in uncertainty and must be improve the model.

Fig. 8 shows forecasting results of electricity consumption from 2018-2036. In Fig. 9 shows the types of power plant of Thailand in future.

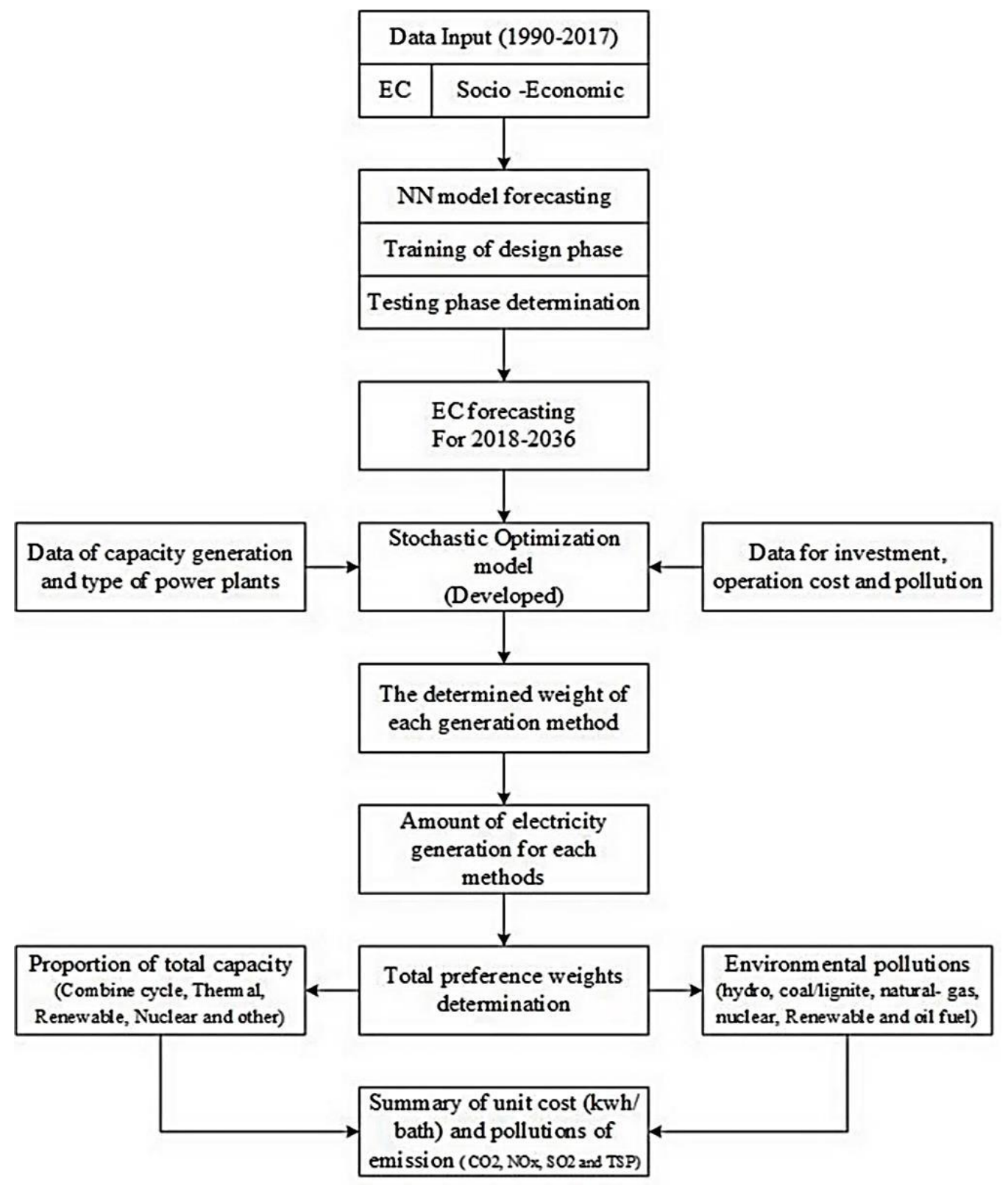

Figure.7 Flowchart for long-term of EC forecasting and stochastic optimization method 


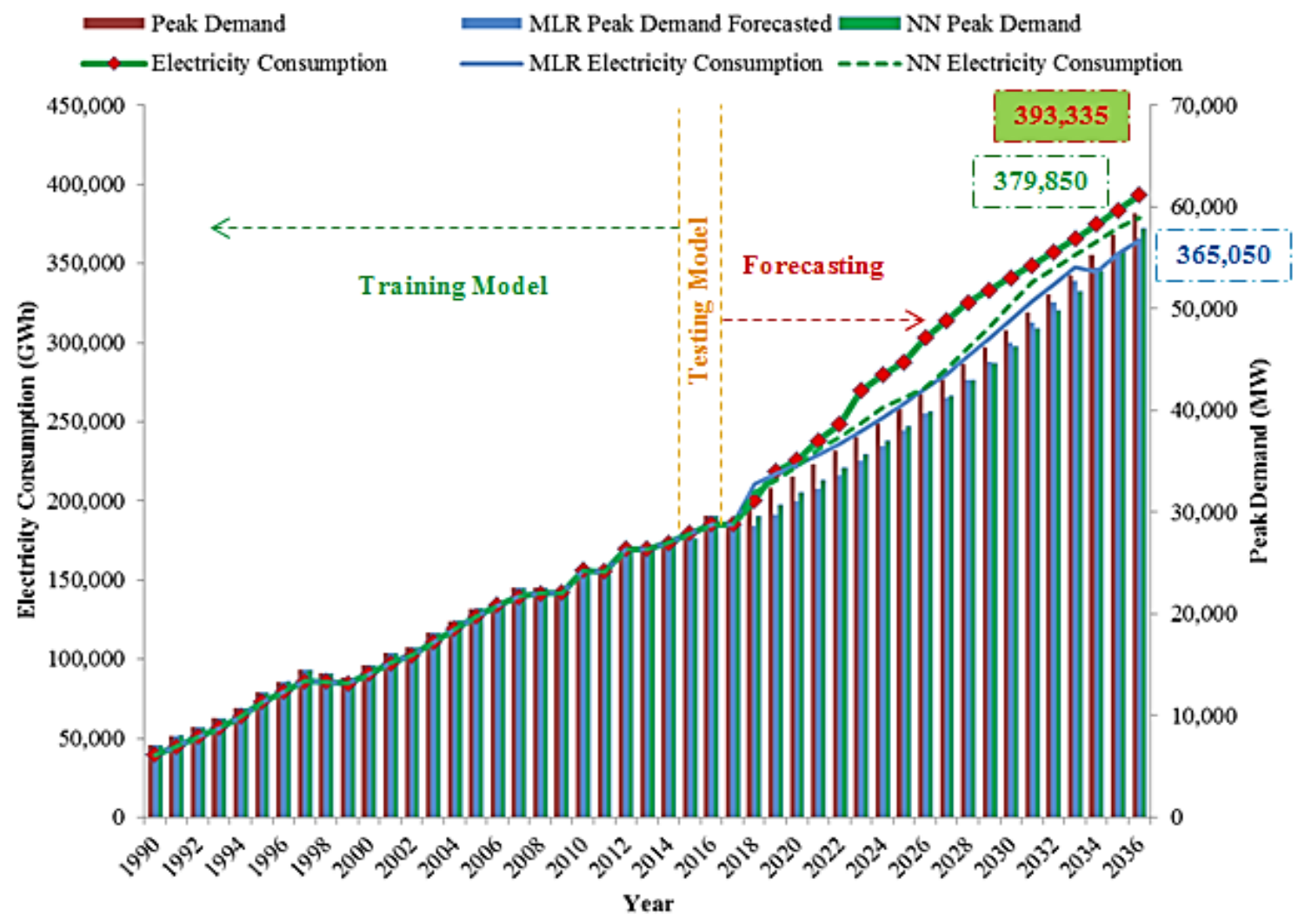

Figure. 8 Forecasting results of electricity consumption.

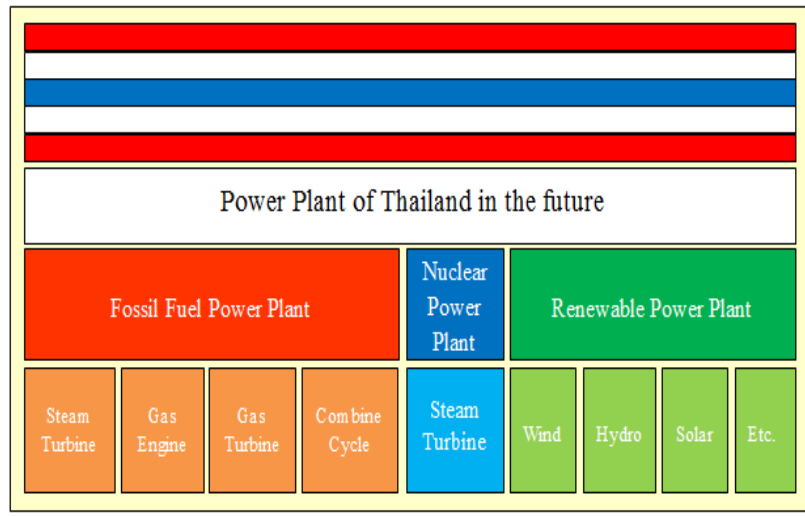

Figure.9 Thailand types of power plants in the future

\section{References}

[1] I. Dincer and C. Acar, "Smart energy systems for a sustainable future", International Journal of Applied Energy, Vol.194, pp.225235, 2017.

[2] S.L. Karunathilake and H.R. Nagahamulla, "Artificial neural networks for daily electricity demand prediction of Sri Lanka", In: Proc. of International Conf. On Advances in ICT for Emerging Regions, pp.1-6, 2017.

[3] M. Erdoğan, and I. Kaya, "A combined fuzzy approach to determine the best region for a nuclear power plant in Turkey", International
Journal of Applied Soft Computing, Vol.39, pp.84-93, 2016.

[4] J. Jewell, V. Vinichenko, D. McCollum, N. Bauer, K. Riahi, T. Aboumahboub, O. Fricko, M. Harmsen, T. Kober, V. Krey, and G. Marangoni, "Comparison and interactions between the long-term pursuit of energy independence and climate policies", International Journal of Nature Energy, Vol. 1, No.6, pp.1-15, 2016.

[5] Electricity Generating Authority of Thailand, EGAT Annual Report, Bangkok, BKK. 2018.

[6] S. Traivivatana, W. Wangjiraniran, S. Junlakarn, and N. Wansophark, "Thailand Energy Outlook for the Thailand Integrated Energy Blueprint (TIEB)", International Journal of Energy Procedia, Vol.138, pp.399404, 2017.

[7] W. Khaenson, S. Maneewan, and C. Punlek, "Assessment of the Environmental Impact of Biomass Electricity Generation in Thailand", International Journal of Renewable Energy Research, Vol.8, No.1, pp.302-312, 2018.

[8] Y. Xu, G. Huang and L. Shao, "A stochastic fuzzy chance-constrained programming model for energy-environment system planning and management in the City of 
Beijing", International Journal of Green Energy, Vol.14, No.2, pp.171-183, 2017.

[9] T. Panklib, "Potential of Agricultural Residues for Small Biomass Power Generation in Thailand", International Journal of Advanced Culture Technology, Vol.4, No.1, pp.1-9, 2016.

[10] M. Alkhathami, "Introduction to electric load forecasting methods", International Journal of Advanced Electrical and Computer Engineering, Vol.2, No.1, pp.1-12, 2015.

[11] S.B. Karwade and M.S. Ali, "Review paper on load forecasting using neuro fuzzy system", International Journal of Electrical and Electronics Engineering. Vol.10, No.3, pp. 38-42, 2015.

[12] M. Rana and I. Koprinska, "Forecasting electricity load with advanced wavelet neural networks", International Journal of Neurocomputing, Vol.182, pp.118-132, 2016.

[13] O.F. Ertugrul, "Forecasting electricity load by a novel recurrent extreme learning machines approach", International Journal of Electrical Power \& Energy Systems, Vol.78, pp.429-435, 2016.

[14] R. Sitharthan, K.R. Devabalaji, and A. Jees, "An Levenberg-Marquardt trained feedforward back-propagation based intelligent pitch angle controller for wind generation system", International Journal of Renewable Energy Focus, Vol. 22, pp.24-32, 2017

[15] L. Yu, Y.P. Li, and G.H. Huang, "A fuzzystochastic simulation-optimization model for planning electric power systems with considering peak-electricity demand: A case study of Qingdao, China", International Journal of Energy, Vol.98, No.1, pp.190-203, 2016.

[16] L. Cooper and M.W. Cooper, Introduction to Dynamic Programming: International Series in Modern Applied Mathematics and Computer Science, Vol.1, Pergamon Press, New York, N.Y. 2016.

[17] T. Fukuba, T. Shiina, and K.I. Tokoro, "Stochastic Programming for Energy Plant Operation", In: Proc. of International Conf. On Theory and Applications of Models of Computation, pp.208-221, 2019.

[18] P. Beraldi, A. Violi, G. Carrozzino, and M.E. Bruni, "A stochastic programming approach for the optimal management of aggregated distributed energy resources", International Journal of Computers \& Operations Research, Vol. 96, pp.200-212, 2018. 